Article

\title{
Transformation through 'Meaningful' Partnership? SDG 17 as Metagovernance Norm and Its Global Health Implementation
}

\author{
Elena Sondermann * and Cornelia Ulbert \\ Institute for Development and Peace, University of Duisburg-Essen, 47048 Duisburg, Germany; \\ E-Mails: elena.sondermann@uni-due.de (E.S.), cornelia.ulbert@uni-due.de (C.U.) \\ * Corresponding author
}

Submitted: 15 September 2020 | Accepted: 2 December 2020 | Published: 26 February 2021

\begin{abstract}
SDG 17 calls for the international community to "strengthen the means of implementation and revitalize the global partnership for sustainable development," emphasizing the role of multi-stakeholder partnerships for achieving the SDGs. Policy documents are replete with statements on the necessity of 'meaningful' engagement, especially with civil society-without clarifying what 'meaningful' stands for. In this article, we develop an analytical approach to partnership as a form and norm of metagovernance. Partnership as a metanorm is about the roles and relations of different sets of actors. We suggest operationalizing the concept of partnership according to different levels of accountability and participation, allowing for a gradual enhancement of the quality of partnership in terms of 'meaningfulness.' We apply our analytical model to the Global Action Plan for Healthy Lives and Well-Being for All (GAP), a fairly new initiative by health and development agencies to accelerate progress towards the health-related targets of the 2030 Agenda. By investigating the development and the early phase of implementing the GAP, we empirically assess if and how the notion of partnership envisioned in the GAP qualifies as 'meaningful' with respect to civil society engagement. From our empirical example, we infer lessons for attaining normative standards of 'meaningfulness' and highlight implications for future research on partnerships.
\end{abstract}

\section{Keywords}

accountability; civil society organizations; global health; metagovernance; participation; partnership; sustainable development goals

Issue

This article is part of the issue "The 2030 Agenda for Sustainable Development: Transformative Change through Sustainable Development Goals?" edited by Thomas Hickmann (University of Utrecht, The Netherlands), Markus Lederer (Technical University of Darmstadt, Germany), Jens Marquardt (Technical University of Darmstadt, Germany), Sandra Schwindenhammer (Justus Liebig University Giessen, Germany) and Sabine Weiland (Catholic University of Lille, France).

(C) 2021 by the authors; licensee Cogitatio (Lisbon, Portugal). This article is licensed under a Creative Commons Attribution 4.0 International License (CC BY).

\section{Introduction}

The Sustainable Development Goals (SDGs) stipulate how we should shape our future social and economic development and what kind of transformations this requires. The challenge, however, lies in the logic of the SDGs: Due to their interconnectedness, it will not suffice to tackle each Goal separately. Therefore, thinking and acting in silos must be overcome. For the transformation envisioned by the SDGs, a global partnership is needed. It is not sufficient to apply and com- bine various modes of governance. Instead, we also have to take the 'governance of governance,' i.e., metagovernance, into account (Christopoulos, Horvath, \& Kull, 2012; Meuleman, 2019; Meuleman \& Niestroy, 2015). SDG 17 asks the international community to "strengthen the means of implementation and revitalize the global partnership for sustainable development." Among the 17 SDGs adopted by the United Nations in 2015, SDG 17 is unique in that it does not address specific policy tasks. Instead, it is about the 'right' way of collaboration between different actors. We argue that partnership 
can be conceptualized as metanorm associated with guidelines on how problems should be tackled and by whom. Thus, as a standard of appropriate behavior, also called metagovernance norm, it defines what good governance of governance should look like (Pantzerhielm, Holzscheiter, \& Bahr, 2020).

The targets associated with SDG 17 relate to financing development, capacity building, the role of technology and trade, and raise several systemic issues. Amongst the latter are two targets $(17.16,17.17)$ that highlight the role of multi-stakeholder partnerships in achieving the SDGs. In this article, we focus on the role of CSOs, which are explicitly addressed as part of multistakeholder partnerships "that mobilize and share knowledge, expertise, technology and financial resources, to support the achievement of the sustainable development goals in all countries, in particular developing countries" (UN Department of Social and Economic Affairs, n.d.). Engagement of civil society is considered crucial both for the achievement of the SDGs and for the political transformation of global governance. However, its role remains unclear and its potential untapped (c.f. Buxton, 2019; Smith, Buse, \& Gordon, 2016). Including CSOs in policy processes is also based on normative considerations that revolve around the concept of legitimacy (Nasiritousi, Hjerpe, \& Bäckstrand, 2016): Incorporating different stakeholder interests and entering into a discursive exchange with civil society representatives enhances the democratic legitimacy of global governance. Their embeddedness in societies on the one hand, and their expertise and independence (or commercial disinterest) on the other, make CSOs guardians of societal interests and watchdogs over decisions taken. We suggest that these ideal-type roles allow for a conceptualization and operationalization of both the processual and the relational dimension of partnership as metanorm. From a normative and conceptual point of view, partnership only becomes 'meaningful,' then, if CSOs are able to perform these roles.

We analyze the role of civil society within one example of a recent metagovernance partnership, the fairly new Global Action Plan for Healthy Lives and Well-being for All, henceforth GAP (WHO, 2019d). This new partnership aims to accelerate country progress on the healthrelated SDGs by enhancing the collaboration among 12 global organizations engaged in health, development and humanitarian relief. For a more effective way of implementing their programs, however, the organizations seek closer engagement with other stakeholders as well, like communities, civil society, or the private sector. By analyzing the potential of the GAP to live up to the normative expectation of creating 'meaningful' partnerships between CSOs and GAP members, we are scrutinizing its 'partnershipability.' The contribution of this article is thus threefold: First, we take a prominent concept of global politics and specify it as form and norm of metagovernance with particular attention to the role of civil society. Second, drawing together existing liter- ature on accountability and participation, we introduce an innovative operationalization of the metanorm 'partnership' which entails standards for empirically assessing civil society engagement against normative expectations with a focus on relational and processual dimensions. Third, we analyze an important and recent example of metagovernance in global health by tracing CSO engagement in the GAP.

Accordingly, we proceed as follows: Section 2 explores key assumptions and conceptualizes partnership as form and norm of metagovernance and the role of CSOs therein. Section 3 operationalizes 'meaningful' partnership as metanorm by introducing participation and accountability, and presents a framework to assess the quality of partnerships in terms of fulfilling the normative standard of 'meaningfulness.' Section 4 employs these theoretical considerations to empirically assess if and how the notion of partnership envisioned in the GAP qualifies as 'meaningful' with respect to civil society engagement. Section 5 discusses the lessons we draw from our empirical example for attaining the norm of 'meaningfulness' and highlights implications for future research on partnerships.

\section{Partnership as Form and Norm of Metagovernance and the Role of Civil Society}

Partnerships are everywhere. Amidst this ubiquity, the following section briefly spells out our understanding of partnership and civil society's role therein. At its core, partnership describes a relationship between different actors, be they individuals, collective actors, states, firms, or other entities. More specifically, partnership is different from other social relationships as it entails a sense of cooperation. It elicits positive connotations of two or more actors sharing responsibility to achieve something (positive) and suggests mutual obligations and the equality of 'partners' involved. Beyond its normative appeal, however, the lack of more precise understandings of the normativity of partnership starkly contrasts with the pervasive application and focal role it plays in global governance. To anchor the following discussion, we think of partnership as both form and norm of global governance extending across levels and modes of governance, from individual partnerships, e.g., public private partnerships, or bilateral aid relationships, to global collective endeavors.

As a form, partnerships in a minimal definition then describe relations between a multitude of diverse actors or stakeholders in a specific, namely cooperative manner. Partnerships are generally understood as innovative forms of governance that bring together different types of actors, from governments to business and civil society, with their respective resources and advantages. Their flexibility, financial resources and strategic approaches are thought to help close the implementation and governance gap and the diversity of participants as shrinking the participation gap in global governance (Bäckstrand, 
2006 , p. 293). It is beyond the scope of this article to delve into the emergence of partnerships in global governance at the end of the 20th century. Suffice to say that it was closely linked to the hope of meeting the aforementioned functional demands at a time of severe criticism of the effectiveness and legitimacy of international institutions (Bäckstrand, 2006). In this article, we zoom in on a hybrid form of global governance with partnership as a manifestation of metagovernance.

As a norm, partnership encompasses more or less specified and formalized principles for practicing cooperative interactions. To understand and scrutinize processes and standards of global governance is of increasing importance as transnational activities and partnerships expand (Scholte, 2011; Tallberg, Bäckstrand, \& Scholte, 2018). There is broad agreement that governance beyond the state requires different mechanisms and yardsticks to ensure and assess legitimacy than national democratic institutions (Scholte, 2014). Traditional notions of formal delegation and direct and hierarchical lines of representation between 'we the people' and governments give way to thinking about pluralist governance forms (Goodhart, 2014; Macdonald, 2018). SDG 17's call to "strengthen the means of implementation and revitalize the global partnership" openly acknowledges partnership as an engagement of a wide range of stakeholders and different governance modes, i.e., as a form of metagovernance. Yet SDG 17 also highlights the intrinsic challenges for the notion of partnership in global governance: Global relations are characterized by unequal roles, power and voice as well as distant or indirect relationships (Rubenstein, 2007). Partnerships in the SDGs are aimed at accelerating progress towards the SDGs, thus addressing sustainability and the well-being of the global population. However, people's situations and vulnerabilities vary starkly, and their voices are unequally heard, depending on their resources and access to sites of decision-making. What, then, should and does the "governance of governance" (e.g., Kooiman \& Jentoft, 2009, p. 818) for the SDGs look like? Due to its central role for the SDG agenda, we argue that it is critical to scrutinize the quality of partnerships beneath the vague but powerful positive associations the partnership concept evokes.

In the remainder of this article, the conceptual and empirical discussions focus on the role of civil society in partnerships. Their role in global governance has carried most of the hope attributed to a legitimization of global governance or 'good' partnerships in the 1990s and early 2000s (Nanz \& Steffek, 2004). NGOs were regarded as addressing democratic deficits of global governance, mostly by giving voice to (underrepresented) societal and even marginalized interests of affected communities and individuals and by drawing attention to unaccounted power (Cutler, Haufler, \& Porter, 1999). Civil society was key to increase pressure on global economic actors, and had an impact on changing the norms and context of debate (Cutler et al., 1999; Keck \& Sikkink, 1998).
The honeymoon period with new actors and modes of global governance has given way to a more critical engagement with multi-stakeholder approaches, and civil society's own influence and accountability have come under scrutiny (Keck \& Sikkink, 1998; Rubenstein, 2007). Participation of CSOs has been criticized for being driven by large 'Northern' NGOs not representative of concerns of the Global South and marginalized interests. On a different level, the quality of participation and the ability to hold other relevant actors accountable have been considered weak and even further diminishing (Buxton, 2019). Among CSOs, on the other hand, there seems to be a growing concern that previous moderate successes in formalizing the partnership norm are not upheld (CPDE, 2020).

Individual regimes, transnational companies and international organizations have individual mechanisms at their disposal to ensure transparency and accountability to members or 'stakeholders.' Already, these are considered insufficient and problematic to satisfy more ambitious or 'democratic' conceptions of transparency and accountability (Goodhart, 2014; Macdonald, 2018; Papadopoulos, 2014). In the case of metagovernance, CSOs' impediments to fulfil their 'democratizing' role in global governance are exacerbated by the involvement of various actors and different types of actors. Overlapping authorities and complex lines of responsibility render visibility and information-gathering difficult. Scrutinizing "the opaque and dynamic forms of power exercised through networked and other non-hierarchical structures" (Macdonald, 2018, p. 456) poses a significant challenge. Against this background, the next section operationalizes the metanorm partnership in order to move beyond mere description towards a critical examination of normative standards for partnership practices.

\section{Operationalizing Partnership through Participation and Accountability}

What does good partnership look like? More precisely, when does a partnership qualify as such, and what is civil society's role? These questions guide the following section. CSOs' two-fold role as 'guardian' and 'watchdog' allows for an assessment of both the processual and the relational dimension of partnership as metanorm. From an ideal-type perspective, as guardians, CSOs' participation should ensure that the concerns of society, of underrepresented and marginalized groups are heard and considered in the process of decision-making. As watchdogs, they are supposed to assume a crucial role in accountability relationships as they transmit information, channel expertise and opinions on the matter at hand and allow for public scrutiny. It goes beyond the scope of this article to detail the theoretical literature on participation and accountability in global governance (e.g., Bovens, Goodin, \& Schillemans, 2014; Haas, 2004; Macdonald, 2018; Scholte, 2011). Drawing on this literature, it is our aim to operationalize standards for practices of 
cooperation in a manner that fits the character of global partnerships and allows for an empirical analysis.

Regarding metagovernance partnerships, members each have their own formal and informal procedures for participation and accountability. Vertical lines of participation and accountability (i.e., principal-agent relations of member states and international organizations) coexist with horizontal checks and balances between members within the partnership, i.e., mutual accountability mechanisms. This leads to a complex system of multipolar relationships and processes (Bruen, Brugha, Kageni, \& Wafula, 2014). For partnerships themselves, as institutionalized forms of networked and multilayered metagovernance, scholars have discussed and called for pluralistic approaches to legitimacy and accountability. These encompass, for instance, courts or other oversight institutions, complaint mechanisms and monitoring systems (Macdonald, 2018), as well as peer-based and reputational mechanisms enhancing collective accountability (Benner, Reinicke, \& Witte, 2004). Among core propositions are increased visibility and accessibility as well as better involvement and empowerment of stakeholders (Slaughter, 2004). It is here that we see civil society's functional role for enhancing partnerships' legitimacy. CSOs then act on behalf of others, namely affected people who lack the capacity to raise their voice and hold actors and institutions to account. CSOs serve as "surrogates" (Rubenstein, 2007, pp. 623-627) or "proxies" (KoenigArchibugi \& Macdonald, 2013, p. 499) during the cooperation process. These practices need to be assessed according to other normative criteria than more traditional vertical mechanisms of delegation and accountability and are always "second-best," as Rubenstein (2007, p. 623) cautions. This becomes clear when problematizing the relationship between proxies and those they are presumably acting on behalf of. Defining and distinguishing 'affected people' is not always possible. And even if it is, ensuring the accountability of proxies speaking in the interests of these affected people is problematic (Papadopoulos, 2014).

Bearing this in mind, we propose a simplistic model of two sets of actors: In this case between formal members of a partnership and those who are proclaimed to be indispensable for its success and legitimacy, i.e., civil society actors. We contend that in a pluralist understanding of legitimate global governance, CSOs as third parties can collect and provide information, thereby creating a public sphere that is necessary for accountability and is otherwise mostly absent from multi-level governance (Hirschmann, 2019, p. 24; Papadopoulos, 2014, pp. 277-278). This again creates a space for monitoring compliance and justification. We now take a closer look at the two interrelated processes of participation and accountability, which we use to operationalize partnership as metanorm.

Regarding participation (left field in Figure 1), we first envision attendance as unidirectional relationships encompassing physical attendance by civil society actors on the one hand and information sharing by formal participants on the other. When the role of CSOs becomes more active and involves a first level of consultation, submitting written or oral reports or opinions, we term this 'engagement' (or 'involvement'). If this is met with feedback, i.e., reflection and discussion, it constitutes a first instance of more active participation. Here, then, CSOs engage in processes of opinion-building and policymaking and we witness forms of interaction. In a next level of consultation, input is allowed for and reflected upon during agenda-setting. 'Meaningful' participation might then even extend to having influence on decision-making. This, however, is neither always possible nor desirable in all forms. The direct influence of nonstate actors in decision-making poses other democratictheoretical questions, which go beyond the scope of this discussion.

What we contend, however, for our topic of 'meaningful' participation is the core issue of responsiveness. While all of the above are labelled participation, we find that for participation to be 'meaningful,' a minimal threshold of responsiveness on the part of formal participants is required. It reflects the capacity of CSOs to bring attention to their opinions and issues, thereby (hopefully) integrating the demands of larger groups of stakeholders. Participation then entails a very different relationship and is more interactive and equal. CSOs are integrated into policy-making processes, giving them an active or possibly even influential role.

We define accountability as a social relationship between an agent who can be held accountable and face consequences, and another agent who holds the former accountable (Bovens, 2007, p. 450). Crucial for accountability (right field in Figure 1 ) are the questions who is holding whom to account for what and how (Hesselmann, 2011). We shorten the debate about 'who' and 'whom' for our conceptual model to CSOs as proxy accountability-holders and formal members as power-wielders and accountability-givers (Rubenstein, 2007). We suggest thinking of the 'how' as a gradual process: Often, the unilateral sharing of information, i.e., transparency, is termed accountability. We refrain from equating transparency and accountability. The former embodies a unidirectional relationship and remains at the discretion of the information-sharer. Only with the idea of answerability, i.e., the position and right to demand information (here by CSOs), do we begin to speak of accountability and of a two-way relationship. If information is then met with mechanisms of response, potentially even including reward or sanction, this signals a different form of relationship. And thirdly, if evaluations lead to an adaptation in policies or behavior, the role of CSOs as proxy accountability-taker can be deemed influential and the relationship more equal. Again, we view responsiveness as a core threshold for 'meaningful' partnership. Together with 'meaningful' participation, 'meaningful' accountability then forms 'meaningful' partnership. 


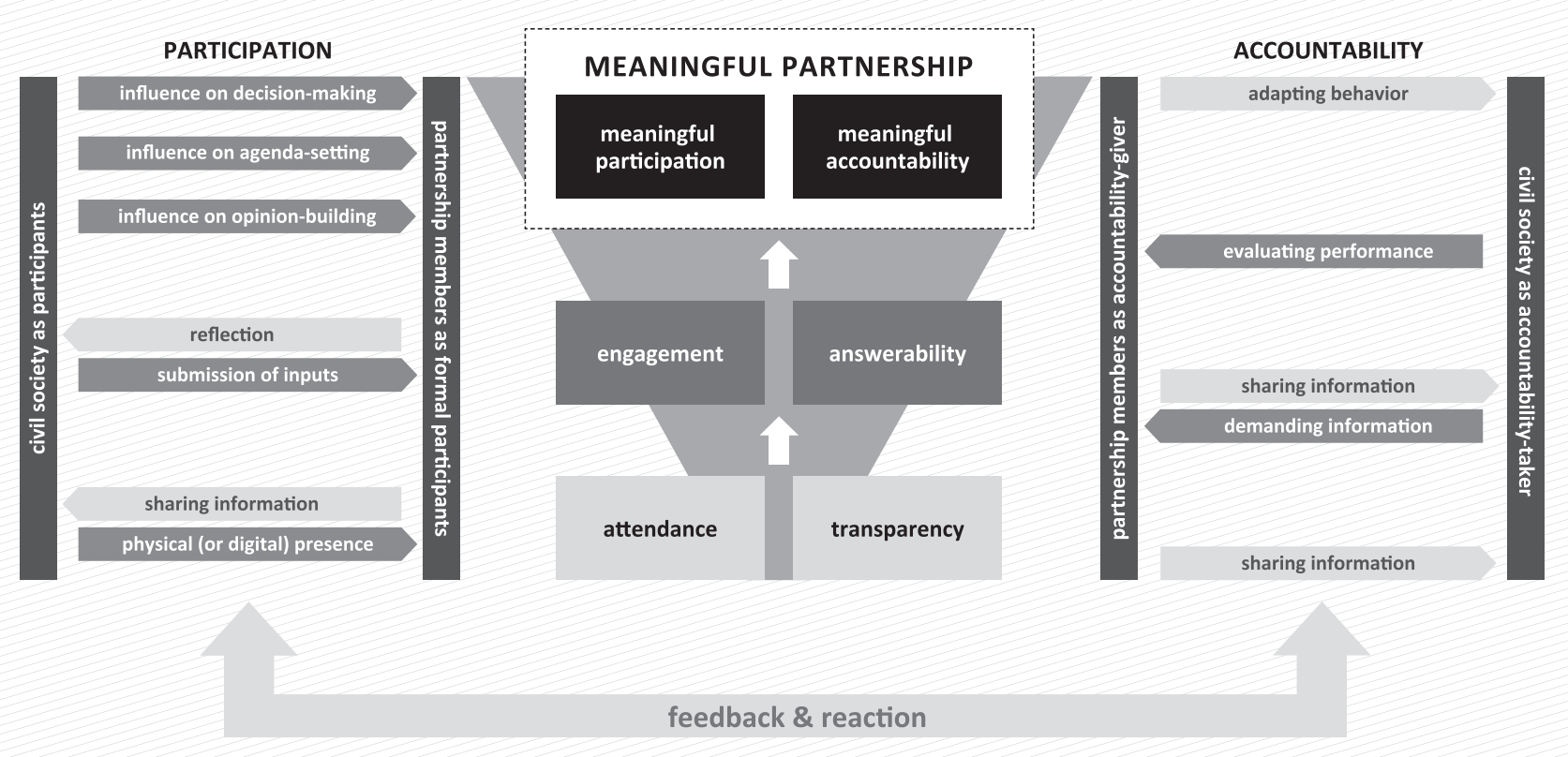

Figure 1. Operationalizing 'meaningful' partnership.

The question of 'for what' one is being held accountable is just as complex as 'how.' Simply put, accountability can refer to outputs and outcomes of discussions and even impacts of policies. Having a clear understanding of roles and responsibilities helps to define the 'for what' and is one core obstacle to accountability in complex governance situations. However, in this article we wish to draw attention to another aspect, i.e., the processual dimensions of accountability and participation and their interrelatedness. In a processual understanding of accountability (and participation), 'what' also encompasses the process itself. Thus, we add another layer to the process of partnership, which is concerned with addressing the context of the partnership, i.e., obstacles to participation and accountability. Are CSOs able to give feedback about a set of context variables, i.e., material constraints for participation, inclusion of core stakeholders, access to discussion and disregard of input, etc.? In relation to accountability, do they have the capacities to follow decision-making processes in a well-informed manner and are they acknowledged in their accountability-taking role? If not, are accountability-takers named at all? On the part of formal participants/accountability-givers: What is their reaction to feedback? Are obstacles addressed and overcome, or are they disregarded? The manner in which these obstacles to participation and accountability are raised and dealt with (feedback and reactions) needs to be included in a critical analysis of the realities of partnerships. They signal different levels of process participation and accountability and allow for an early assessment of the quality of partnership, i.e., its 'meaningfulness.' The example we have chosen to illustrate this is the GAP on SDG 3.

\section{4. 'Meaningful' Partnership? Roles and Relations in the Global Action Plan for Health}

The GAP on SDG 3 is a paradigmatic example of studying 'meaningful' partnership since the two concepts of participation and accountability are among its defining features and primary goals. For the collaborating agencies, attaining both contributes to the successful achievement of SDG 3 and other health-related targets. We traced the process of developing the GAP and the beginning of the implementation phase by analyzing the available primary (text and video) sources published by the participating organizations and civil society actors (e.g., documents, reports, records and recordings of meetings, correspondence, working papers, blogs, evaluations). The objective was to uncover how the process of engaging with civil society actors unfolded within our analytical framework, which roles the different actors were taking and what kind of relations were evolving between the participating agencies and CSOs. By analyzing the origin and implementation of the GAP, the intricacies of formal partnership members engaging with civil society become visible. In the following, we will briefly introduce the GAP and the relevance assigned to CSOs in its implementation, before we discuss if it meets the criteria that we spelled out above for 'meaningful' participation and accountability.

It was only in April 2018 that the heads of the governments of Germany, Ghana and Norway approached the WHO to accelerate the process towards achieving SDG 3. In a letter addressed to WHO Director-General Tedros Adhanom Ghebreyesus, they proposed the development of a joint Global Action Plan for Healthy Lives and Well-Being, thus uniting relevant actors in global health to "streamline 
their efforts" (Merkel, Akufo-Addo, \& Solberg, 2018). In September 2018, the WHO released an outline Towards a Global Action Plan for Healthy Lives and Wellbeing for All: Uniting to Accelerate Progress towards the Health-Related SDGs (WHO, 2018c), followed by the actual GAP document entitled Stronger Collaboration, Better Health: Global Action Plan for Healthy Lives and Well-being for All: Strengthening Collaboration among Multilateral Organizations to Accelerate Country Progress on the Health-Related Sustainable Development Goals in October 2019 (WHO, 2019d). In essence, the GAP is aimed at furthering the collaboration between 12 global organizations that work in the fields of health, development and humanitarian relief (GAVI, the Vaccine Alliance, Global Financing Facility, the Global Fund, UNAIDS, UNDP, UNFPA, UNICEF, Unitaid, UN Women, World Bank, World Food Programme, WHO). This collaboration rests on four commitments: engage, accelerate, align, account. The actual work revolves around seven 'accelerator themes': primary health care, sustainable financing for health, community and civil society engagement, determinants of health, innovative programming in fragile and vulnerable settings and for disease outbreak responses, research and development, innovation and access, and, lastly, data and digital health.

The history of the development of the GAP shows some of the obstacles CSOs face when participating in global policy processes-in this case at the metagovernance level. CSOs are usually defined as non-state, not-for-profit, voluntary organizations. This distinguishes them from philanthropic organizations or actors from the private sector. Although compared to the latter, CSOs usually have less financial and human resources at their disposal, the list of contributions they are expected to make in providing public goods and reaching the SDGs is quite long (e.g., Greer, Wismar, Pastorino, \& Kosinska, 2017; Smith et al., 2016). Since they are seen as the group of actors closest to the needs of communities, CSOs are attributed the role of giving marginalized and vulnerable groups a voice, thereby ensuring that no one will be left behind (e.g., Greer et al., 2017). However, the WHO especially has a long-standing history of confrontation with civil society about its engagement with non-state actors. To ease civil society's concerns about undue influence of corporate actors and private foundations on the WHO's work, the organization adopted a Framework of Engagement with Non-State Actors in 2016 (WHO, 2016). Since then, it has continuously developed its regulatory framework (e.g., WHO, 2018a).

The task of devising a GAP was assigned to the WHO by the governments of three member states. The WHO, like other international organizations, is answerable to its principals, the member states. Formally, the accountability-takers are the members of the participating agencies, and because of scarce resources and lack of time, international organization secretariats prioritize with whom to interact extensively. This puts CSOs in a disadvantageous position, for two reasons. Firstly, they are not formal members and as such, they do not only have to lobby to be heard; they also have to work on establishing rules and procedures for being admitted, as the example of the Framework of Engagement with Non-State Actors (WHO, 2016) shows. Secondly, 'civil society' is an umbrella term. It consists of vastly different groups of actors that vary in size and resources. Usually, they also differ in opinion, which makes it hard for their counterparts to identify positions that can be taken up further and acted upon.

As far as the GAP is concerned, the group of 'formal participants' in this new partnership consists of very distinct multilateral organizations, which want to "deliver results" at country level by a "more purposeful, systematic, transparent and accountable collaboration" (WHO, 2019d, p. ix). However, in order to achieve this, the GAP "recognizes that other stakeholders, including communities, civil society and the private sector, make vital contributions to achieving the SDGs and promotes closer engagement with these key partners" (WHO, 2019d, p. xiv). In accordance with the WHO's Thirteenth General Programme of Work 2019-2023: Promote Health, Keep the World Safe, Serve the Vulnerable (WHO, 2019e) the organization has proclaimed "a new era of partnership between WHO and civil society" (WHO, 2018b). The importance of tapping into the resources of CSOs is also acknowledged in accelerator theme three of the GAP, which focuses on community and civil society engagement. There, the GAP explicitly refers to SDG 17 and SDG target 16.7 (inclusive, participatory decisionmaking; WHO, 2019d, p. 62).

In the GAP document, the signatories commit to "meaningful engagement" with communities and civil society, which exists "when participants manage to influence decisions on issues that affect their lives" (WHO, 2019d, p. 62). In our conceptual discussion above, we defined participation as 'meaningful' when civil society succeeds in exerting influence on opinion-building, agenda-setting and decision-making. Similarly, accountability relationships become 'meaningful' when an accountability-giver adapts its behavior after the accountability-taker has evaluated its performance. For our empirical analysis of the 'partnershipability' of the GAP, we have translated our operationalization into observable indicators. To assess the level of CSO engagement, we first looked at the formal arrangements for CSO participation as specified in the published documents. In a second step, we took into account processes of interaction, mainly in the form of oral and written speeches, inputs and background information. We evaluated CSOs' inputs and consultation and their reflection in later official documents and tried to establish what kind of 'influence' they had on the process and to assess the quality of their participation.

As far as the question of 'meaningful' participation is concerned, for the period between the release of GAP phase one in October 2018 and the launch of the GAP at the UN General Assembly in September 2019, we can 
witness activities on all three levels we distinguished for analytical reasons (see upper field of Figure 2). With respect to attendance, on both occasions, civil society actors were present at the events linked to the publication of both documents and entered into discussions about the GAP. However, it was up to the CSOs to offer their coordinated engagement and expertise in a joint letter to WHO-DG Tedros (Civil Society Engagement Mechanism, 2018). Moreover, time constraints were a factor to consider. Originally, the three heads of governments had asked for the release of a GAP back in October 2018, which turned out to be unrealistic. Therefore, the final document was scheduled for the September 2019 meeting of the UN General Assembly, hence setting the timeframe for developing the GAP. For CSOs, this meant that they had to act quickly if they wanted to engage in opinion-building. Organizing such a disparate group of actors, however, requires resources and above all a coordinating body with the ability to engage, assess and lead. Since the GAP appeared as an item on the agenda for the January 2019 meeting of the WHO's Executive Board, civil society held a strategic meeting in New York in December 2018, organized and supported by the Civil Society Engagement Mechanism of the International Health Partnership for UHC2030 and the Global Fund Advocates Network. Shortly afterwards, in February 2019, the Civil Society Engagement Mechanism established an advisory group of civil society and community representatives to focus the work of civil society on the GAP. The advisory group had the two-fold mission of collecting input and offering itself as a leading voice of civil society, which worked quite effectively, at least for building and voicing the opinions of CSOs.

On the level of formal engagement, with respect to the very tight timeframe, it seems that the WHO and the other GAP organizations had not planned a consultation process. However, especially when CSOs advocated for a public consultation, the WHO consented to hold it-albeit at very short notice and only for an extremely limited period (WHO, 2019b). Nevertheless, civil society was able to influence the agenda-setting process and submit its input subsequently. But did CSO participation also meet the 'gold standard' of influencing decisionmaking? Here, the picture is unclear. The WHO published a compilation of all submissions in the consultation (WHO, 2019c), highlighting which feedback "was taken into account in the development" of the GAP (WHO, 2019a, p. 11), including issues raised by CSOs. However, this was done only in September 2019, when the GAP had already been scheduled for release. Therefore, it is unclear if and to what extent the input of CSOs had an impact while the GAP was being finalized.

Nevertheless, on paper, the frequency of interaction on all levels of participation in the 'constitution phase' of the GAP seems remarkable (see third column of Figure 2). Still, there are CSO representatives who are critical of the process and their relationship to the WHO as the organization leading the process (Haase \& Eger, 2019; Schwarz,
2019). This criticism does not seem to be unfounded, since it was only due to the CSOs' perseverance that they were able to participate in this process at all. One could argue that it is quite indicative that the GAP document for the first phase only spelled out three commitments, i.e., align, accelerate, account; whereas after the somewhat enforced engagement with civil society, the final document also lists a fourth commitment: engage.

With respect to the quality of CSO participation, a one-day consultation which GAP organizations held in New York in April 2019 is informative. This consultation with non-state actors was limited to three out of seven accelerator themes with a focus on community and civil society engagement. The organizations that were able to attend were the 'usual' NGOs, like World Vision International, the International Planned Parenthood Federation or Save the Children, which are active in New York or able to travel there. In other words: The GAP organizations not only decided to limit the agenda. In addition, access to the event was based on available resources, which also narrowed the number of $\mathrm{CSO}$ present. One could argue that although CSOs were able to participate, their participation was still not truly 'meaningful' since there was no reaction from the GAP organizations to the feedback from CSOs in the public consultation. Another indicator of this is the fact that while the Accelerator Discussion Paper 3 on Community and Civil Society Engagement lists 'contributions' from civil society representatives (UNAIDS \& WHO, 2019) "civil society came on board only after the development of the accelerators and the discussion papers" (Koutsoumpa, Nsbirwa, Schwarz, Ssemakula, \& Musoke, 2020, p. 16, emphasis added).

The second factor contributing to 'meaningful' partnership relates to accountability. In this early phase of implementation, one year after the release of the GAP, there are almost no mechanisms in place to make the GAP organizations accountable in a 'meaningful' way (compare lower field of Figure 2). The GAP organizations commissioned a Joint Evaluability Assessment, which was finalized in July 2020. Besides the need to agree on how to operationalize the GAP and "make it concrete" (York, Hofer, \& Watkins, 2020, p. 13), the evaluators highlight the "distinct lack of clear accountabilities (and incentives) in the GAP partnership to ensure timely follow-up and actions once decisions are taken" (York et al., 2020, p. 14). Thus, it remains open who is in a formal position to demand information, i.e., to whom the GAP organizations are answerable. Therefore, CSOs do not know who to address even in their role as 'surrogates' or 'proxy' accountability-takers.

In May 2020, the WHO published an overview of the operating model of the GAP (GAP, 2020) in an attempt to specify how the GAP signatories should align to collaborate more closely at country level. The operating model defines various groups at different levels and assigns specific roles and responsibilities to them (cf. also WHO, 2020b, pp. 34-35). However, no information is available 
LEVEL OF PARTICIPATION / ACCOUNTABILITY

OPERATIONALIZATION WITH INDICATORS

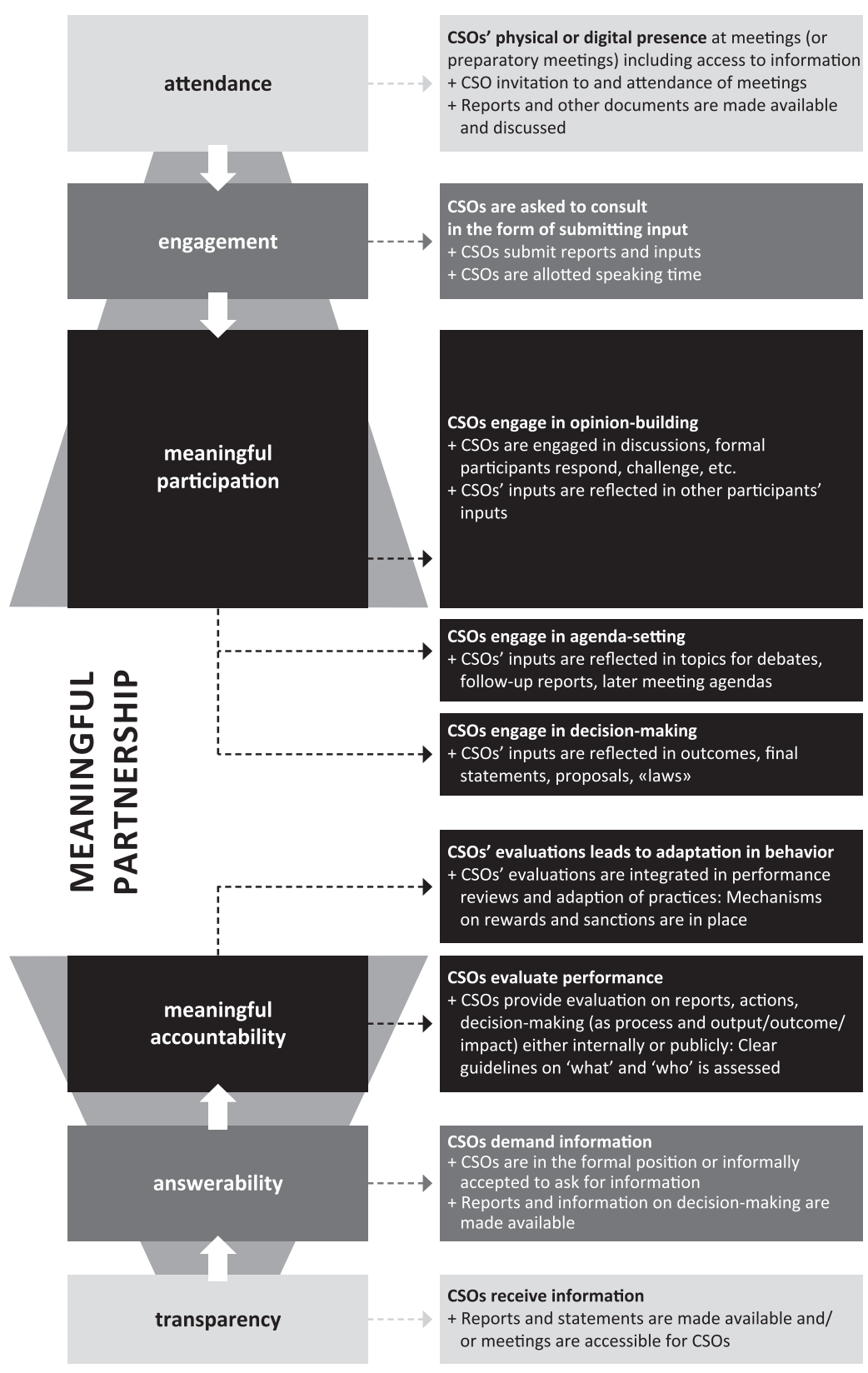

CSO ENGAGEMENT IN DEVELOPMENT AND IMPLEMENTATION OF SDG GAP

10/2018: CSEM endorses the GAP initiative; of offers coordinated CSO engagement and expertise for developing the GAP in a letter to WHO-DG Tedros 10/2018, Berlin: Release of GAP phase 1 at World Health Summit 07/2019, New York: HLPF Side Event to showcase GAP to member states and other stakeholders
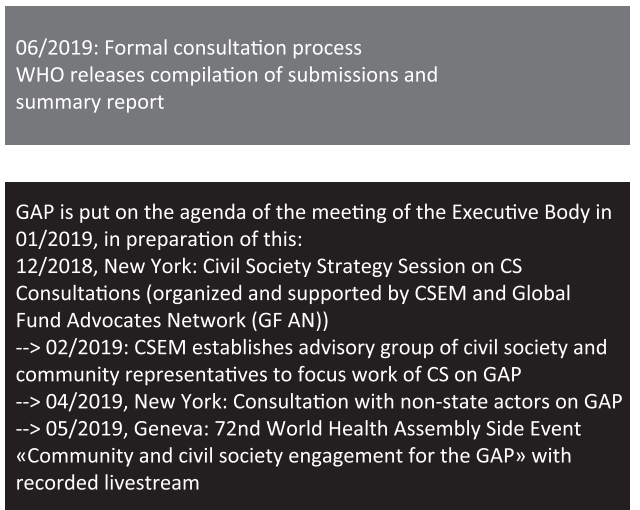

CSOs advocate for a formal consultation process, which is subsequently held
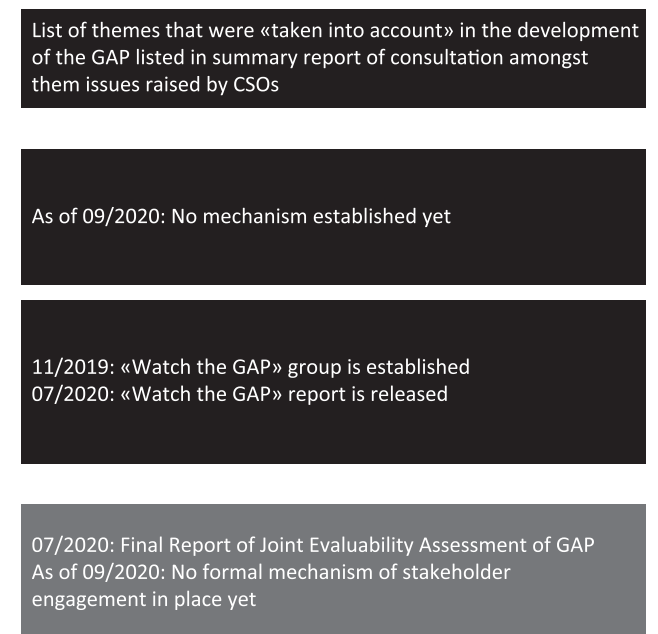
As of 09/2020: No formal mechanism of stakeholder engagement in place yet

05/2020: WHO publishes an Overview of GAP Operating Model 09/2020: WHO publishes First Progress Report on GAP

Figure 2. Assessing the 'partnershipability' of the GAP.

or accessible to civil society on the actual workings and proceedings of these groups. In September 2020, the WHO released a first progress report on implementation of the GAP over the year since its adoption (WHO, 2020b). In it, the GAP is characterized as an ambitious joint commitment that "promotes a cultural shift within the existing health architecture towards more purposeful and systematic collaboration among the 12 agencies and with countries" (WHO, 2020b, p. 1). This indicates that more internal barriers have to be overcome by the GAP signatories to achieve closer alignment of each organization's operations in selected countries. Increasing the incentives for stronger collaboration among the agen- cies is one of the challenges to implementing the GAP mentioned in the progress report. Engaging civil society and increasing transparency and accountability are others (WHO, 2020b, p. 45).

To enhance civil society engagement, the GAP agencies intend to collaborate with the Civil Society Engagement Mechanism (WHO, 2020b, p. 24), which acted as a successful mechanism for participation in developing the GAP. However, in November 2019, other sections of civil society established a Watch the GAP group, which published a first critical evaluation of the GAP in July 2020 (Koutsoumpa et al., 2020). Even without a formal mandate, civil society actors are already 
scrutinizing the GAP. What is missing again, however, is GAP organizations' feedback on the civil society report.

In sum, there were several entry-points for CSOs during the process of developing the GAP, which allowed for interaction with the GAP organizations. Superficially, it seems that civil society was able to participate in a 'meaningful' way. However, from the perspective of civil society actors, the story reads somewhat differently: CSO participation created the appearance of legitimacy while inclusion of their voice was neither actively sought nor formalized. Civil society, as a group of actors that are under-resourced and overstretched in many ways, had to struggle to make itself heard. As far as accountability is concerned many important questions are still unanswered. If the inclusion of stakeholders is seen as critical for success, who then should be included and how? The GAP organizations are committed to reporting and monitoring. But to whom, and how can it be enforced? Are there any consequences for non-delivery? Furthermore, a broader discussion on roles and responsibilities of the GAP partners is lacking. To deliver results, the GAP organizations themselves see the need to enhance their ability to engage with stakeholders. As far as the standard of 'meaningfulness' is concerned, this relates particularly to reacting to CSO feedback in the process.

As the discussion of the GAP shows, there are opportunities and pitfalls associated with realizing the metanorm of 'meaningful' partnership. We will discuss these in our concluding section and sketch out some of the conditions for attaining 'meaningful' participation and accountability, as well as implications for future research on partnerships.

\section{Conclusion}

To better understand and assess the realities of multistakeholder engagement and CSOs' role therein, we proposed to think of 'partnership' not only as a form but also as a norm of metagovernance. This allowed us to focus on roles and relationships of actors in a partnership, understood as a process of governance. Therefore, we operationalized the concept of partnership according to different levels of accountability and participation, allowing for a gradual enhancement of the quality of partnership in terms of 'meaningfulness.' We applied our analytical model to the GAP, which is still in the making. This opens up the space to develop it further with a clearer notion of what might be necessary to make the partnership and engagement with civil society 'meaningful.' Even more so, since the GAP has gained traction as a role model for a crucial component of the current responses to the coronavirus pandemic, namely the The Access to Covid-19 Tools (ACT) Accelerator (WHO, 2020a).

The example of the GAP illustrates that with respect to participation, there is already a considerable amount of interaction between the formal members of a partnership and CSOs. However, since CSO participation remains informal, it was selective, in terms of permanence and spectrum of voices. The latter makes it very hard for formal members of partnerships to identify the 'right' CSOs to engage with. The current WHO process of engaging with civil society to develop a Handbook on Social Participation for Universal Health Coverage points in a promising direction of formalizing rules and procedures to make CSO engagement more transparent and less random (UHC2030, n.d.; WHO, 2018b). CSOs cannot act as 'proxy' accountability-takers if there are no mechanisms of accountability in place, and if no obligation for formal members to react to input provided by 'informal' participants exists.

Another observation worth emphasizing relates to the competition over resources and their allocation. Resources are scarce not only on the part of CSOs but also on the part of the GAP agencies. Making more resources available for all stakeholders in multistakeholder processes is somewhat illusionary. It seems more appropriate to identify stakeholders that have been 'left behind' so far. The question of defining who falls into the category of 'left behind' touches on a fundamental concern of global governance: What should just and fair governance look like, and who has the authority to set the normative standards for appropriate behavior? 'Leave no one behind' is a central principle of the 2030 Agenda and the SDGs. Therefore, in order to achieve the SDGs, it is essential to identify stakeholders and groups who are left behind. Within the multilateral framework of the United Nations, "Ileaving no one behind' not only entails reaching the poorest of the poor, but also seeks to combat discrimination and rising inequalities within and among countries, and their root causes" (UN System Chief Executives Board for Coordination, 2017, p. 31). Subsequently, this framework was operationalized for UN country teams (UN Sustainable Development Group, 2019): However, identifying those who are 'left behind' in practice always takes place in a setting with political, socio-economic or cultural struggles over power and resources at country, regional or global levels of governance.

Finally, we would like to highlight another implication of our discussion: Conceptualizing partnership as metanorm, and assessing the GAP accordingly, opens up new possibilities to put partnership and the GAP's partnershipability into (historical) perspective and to draw lessons from other examples. Although the GAP is hailed as a new and innovative form of partnership, earlier attempts to formalize and institutionalize cooperative relationships in global governance are manifold. For instance, in the field of development cooperation and health cooperation, the 'aid effectiveness norm' was endorsed at summits and assessed through ensuing monitoring processes between 2005 and 2011, leading to the Global Partnership for Effective Development Cooperation (Abdel-Malek, 2015; Barnes \& Brown, 2011). The goal was to establish a global partnership promoting recipient countries' ownership by 
harmonizing and aligning donor practices and enhancing mutual accountability. Civil society was integrated only later in the process, due to CSO pressure. Subsequently, CSOs were successful in establishing a rather prominent position in the Global Partnership for Effective Development Cooperation. Even though the norm has "declined and potentially died" (Brown, 2020, p. 1230), the GAP terms and language are reminiscent of the aid effectiveness vocabulary in many ways. Further research on earlier and current alternative forms of 'global partnerships' and their level and quality of participation and accountability seems promising to identify obstacles to 'meaningful partnership' as a metagovernance norm in a comparative and more systematic way.

\section{Acknowledgments}

We acknowledge the support of the Open Access Publication Fund of the University of Duisburg-Essen.

\section{Conflict of Interests}

The authors declare no conflict of interests.

\section{References}

Abdel-Malek, T. (2015). The global partnership for effective development cooperation: Origins, actions and future prospects. Bonn: German Development Institute.

Bäckstrand, K. (2006). Multi-stakeholder partnerships for sustainable development: Rethinking legitimacy, accountability and effectiveness. European Environment, 16(5), 290-306.

Barnes, A., \& Brown, G. W. (2011). The idea of partnership within the Millennium Development Goals: Context, instrumentality and the normative demands of partnership. Third World Quarterly, 32(1), 165-180.

Benner, T., Reinicke, W. H., \& Witte, J. M. (2004). Multisectoral networks in global governance: Towards a pluralistic system of accountability. Governance and Opposition, 39(2), 191-210.

Bovens, M. (2007). Analysing and assessing accountability: A conceptual framework. European Law Journal, 13(4), 447-468.

Bovens, M., Goodin, R. E., \& Schillemans, T. (Eds.). (2014). The Oxford handbook of public accountability. Oxford: Oxford University Press.

Brown, S. (2020). The rise and fall of the aid effectiveness norm. European Journal of Development Research, 32, 1230-1248.

Bruen, C., Brugha, R., Kageni, A., \& Wafula, F. (2014). A concept in flux: Questioning accountability in the context of global health cooperation. Globalization and Health, 10(73), 1-15.

Buxton, N. (2019). Multistakeholderism: A critical look (Workshop Report). Amsterdam: Transnational Institute.
Christopoulos, S., Horvath, B., \& Kull, M. (2012). Advancing the governance of cross-sectoral policies for sustainable development: A metagovernance perspective. Public Administration and Development, 32(3), 305-323.

Civil Society Engagement Mechanism. (2018, December 2). Civil society and the Global Action Plan for Healthy Living and Well-being for All. Geneva: Civil Society Engagement Mechanism. Retrieved from https://csemonline.net/wp-content/uploads/2019/ 01/Letter-to-Dr-Tedros-Global-Action-Plan_ Oct2nd.pdf

CPDE. (2020). Strategic plan 2020-2023: Leveraging effective development cooperation for inclusive partnerships to deliver the 2030 agenda. Quezon City: CSO Partnership for Development Effectiveness.

Cutler, A. C., Haufler, V., \& Porter, T. (Eds.). (1999). Private authority and international affairs. Albany, NY: SUNY Press.

GAP. (2020). Overview of GAP operating model. World Health Organization. Retrieved from https://www.who.int/docs/default-source/globalaction-plan/operating-model-graph-and-narrative--web-version.pdf?sfvrsn=2c02de89_4

Goodhart, M. (2014). Accountable international relations. In M. Bovens, R. E. Goodin, \& T. Schillemans (Eds.), The Oxford handbook of public accountability (pp. 289-304). Oxford: Oxford University Press.

Greer, S. L., Wismar, M., Pastorino, G., \& Kosinska, M. (Eds.). (2017). Civil society and health: Contributions and potentials. Geneva and Copenhagen: World Health Organization and European Observatory on Health Systems and Policies.

Haas, P. M. (2004). Addressing the global governance deficit. Global Environmental Politics, 4(4), 1-15.

Haase, M., \& Eger, H. (2019). Global action or dissatisfaction? G2H2 Geneva Global Health Hub. Retrieved from http://g2h2.org/posts/global-actionor-dissatisfaction

Hesselmann, E. (2011). The limits of control: The accountability of foundations and partnerships in global health. In S. Rushton \& D. O. Williams (Eds.), Partnerships and foundations in global health governance (pp. 228-252). Houndmills: Palgrave-Macmillan.

Hirschmann, G. (2019). Guarding the guards: Pluralist accountability for human rights violations by international organisations. Review of International Studies, 45(1), 20-38.

Keck, M. E., \& Sikkink, K. (1998). Activists beyond borders: Advocacy networks in international politics. Ithaca, NY and London: Cornell University Press.

Koenig-Archibugi, M., \& Macdonald, K. (2013). Accountability-by-proxy in transnational non-state governance. Governance, 26(3), 499-522.

Kooiman, J., \& Jentoft, S. (2009). Meta-governance: Values, norms and principles, and the making of hard choices. Public Administration, 87(4), 818-836.

Koutsoumpa, M., Nsbirwa, D., Schwarz, T., Ssemakula, 
M., \& Musoke, L. S. (2020). Watch the GAP! A critical civil society perspective on the development, potential impact and implementation of the 'Global Action Plan for Healthy Lives and Well-Being for All.' Amsterdam: Wemos.

Macdonald, K. (2018). Accountability in global economic governance. In C. Brown, R. Eckersley, \& K. Macdonald (Eds.), The Oxford handbook of international political theory (pp. 452-466). Oxford: Oxford University Press.

Merkel, A., Akufo-Addo, N. A. D., \& Solberg, E. (2018). Letter to Dr. Tedros. Berlin: Bundesregierung. Retrieved from https://www.bundesregierung.de/resource/ blob/997532/1007244/6c2d1e27d60f916d6e9b7 bafa8aea64e/2018-04-19-brief-who-englischdata.pdf?download $=1$

Meuleman, L. (2019). Metagovernance for sustainability: A framework for implementing the Sustainable Development Goals. London and New York, NY: Routledge.

Meuleman, L., \& Niestroy, I. (2015). Common but differentiated governance: A metagovernance approach to make the SDGs work. Sustainability, 7(9), 12295-12321.

Nanz, P., \& Steffek, J. (2004). Global governance, participation and the public sphere. Government and Opposition, 39(2), 314-335.

Nasiritousi, N., Hjerpe, M., \& Bäckstrand, K. (2016). Normative arguments for non-state actor participation in international policymaking processes: Functionalism, neocorporatism or democratic pluralism? European Journal of International Relations, 22(4), 920-943.

Pantzerhielm, L., Holzscheiter, A., \& Bahr, T. (2020). Power in relations of international organisations: The productive effects of 'good' governance norms in global health. Review of International Studies, 46(3), 395-414.

Papadopoulos, Y. (2014). Accountability and multi-level governance. In M. Bovens, R. E. Goodin, \& T. Schillemans (Eds.), The Oxford handbook of public accountability (pp. 273-288). Oxford: Oxford University Press.

Rubenstein, J. (2007). Accountability in an unequal world. Journal of Politics, 69(3), 616-632.

Scholte, J. A. (Ed.). (2011). Building global democracy? Civil society and accountable global governance. Cambridge: Cambridge University Press.

Scholte, J. A. (2014). Reinventing global democracy. European Journal of International Relations, 20(1), 3-28.

Schwarz, T. (2019). The making of a "Global Action Plan for Healthy Lives and Well-being for All": We are still not amused. G2H2 Geneva Global Health Hub. Retrieved from http://g2h2.org/posts/still-notamused

Slaughter, A.-M. (2004). Disaggregated sovereignty: Towards the public accountability of global government networks. Government and Opposition, 39(2), 159-190.

Smith, J., Buse, K., \& Gordon, C. (2016). Civil society: The catalyst for ensuring health in the age of sus- tainable development. Globalization and Health, 12. https://globalizationandhealth.biomedcentral.com/ articles/10.1186/s12992-016-0178-4

Tallberg, J., Bäckstrand, K., \& Scholte, J. A. (Eds.). (2018). Legitimacy in global governance: Sources, processes, and consequences. Oxford: Oxford University Press.

UHC2030. (n.d.). Civil society consultation on handbook on social participation for UHC. UHC2030. Retrieved from https://www.uhc2030.org/what-wedo/voices/accountability/civil-society-consultationon-handbook-on-social-participation-for-uhc

UN Department of Social and Economic Affairs. (n.d.). SDG 17: Strengthen the means of implementation and revitalize the global partnership for sustainable development: Targets and indicators. UN DESA. Retrieved from https://sdgs.un.org/goals/goal17

UN Sustainable Development Group. (2019). Leaving no one behind: A UNSDG operational guide for UN country teams. New York, NY: United Nations. Retrieved from https://unsdg.un.org/sites/default/ files/Interim-Draft-Operational-Guide-on-LNOBfor-UNCTs.pdf

UN System Chief Executives Board for Coordination. (2017). Leaving no one behind: Equality and nondiscrimination at the heart of sustainable development. New York, NY: United Nations.

UNAIDS, \& WHO. (2019). Accelerator discussion paper 3: Community and civil society engagement. WHO. Retrieved from https://www.who.int/docs/defaultsource/global-action-plan/acceletator-paper-3community-civil-society-engagement-170620191.pdf?sfvrsn=aea20165_2

WHO. (2016). Framework of engagement with non-state actors (WHA69.10), 2016, May 28. Geneva: World Health Organization.

WHO. (2018a). Handbook for non-state actors on engagement with the World Health Organization. Geneva: World Health Organization.

WHO. (2018b). Together for the triple billion: A new era of partnership between WHO and civil society. Geneva: World Health Organization. Retrieved from https://civilsociety4health.org/app/uploads/2018/ 12/WHO-cso-report.pdf

WHO. (2018c). Towards a Global Action Plan for Healthy Lives and Well-being for All: Uniting to accelerate progress towards the health-related SDGs. Geneva: World Health Organization.

WHO. (2019a). Public discussion on the Global Action Plan for Healthy Lives and Well-being for All. WHO. Retrieved from https://www.who.int/docs/ default-source/global-action-plan-update-sept19/ public-consultation-report-gap-september20191.pdf?sfvrsn=3a968bfb_2

WHO. (2019b, May 16). Response letter of WHO Director-General Dr. Tedros to Ms. Loyce Pace and Dr. Justin Koonin. Neuchâtel: CSEM. Retrieved from https://csemonline.net/wp-content/uploads/2019/ 05/DG_reponse-letter.pdf 
WHO. (2019c). SDG GAP public consultation comments. WHO. Retrieved from https://www.who.int/docs/ default-source/global-action-plan/sdg-gap-publicconsultation-comments-all.pdf?sfvrsn=2e1feb73_2

WHO. (2019d). Stronger collaboration, better health: Global Action Plan for Healthy Lives and Well-being for All: Strengthening collaboration among multilateral organizations to accelerate country progress on the health-related Sustainable Development Goals. Geneva: World Health Organization.

WHO. (2019e). Thirteenth general programme of work 2019-2023: Promote health, keep the world safe, serve the vulnerable. Geneva: World Health Organization.
WHO. (2020a). The access to COVID-19 tools (ACT) accelerator. World Health Organization. Retrieved from https://www.who.int/initiatives/act-accelerator

WHO. (2020b). Stronger collaboration, better health: 2020 progress report on the Global Action Plan for Healthy Lives and Well-being for All. Geneva: World Health Organization.

York, N., Hofer, S., \& Watkins, J. (2020). Joint evaluability assessment of the Global Action Plan for Healthy Lives and Well-being for All. New York, NY: UNFPA. Retrieved from https://www.unfpa.org/sites/ default/files/admin-resource/SDG_GAP_JEA_ FINAL_report.pdf

\section{About the Authors}

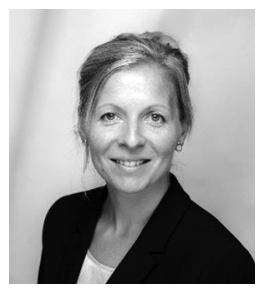

Elena Sondermann is a Political Scientist and Researcher at the Institute for Development and Peace (INEF) at the University of Duisburg-Essen. Elena's work focuses on global and international cooperation, mainly in the fields of global development politics and global health governance. She has a particular interest in actors' roles and relationships. Her research critically engages with paradigms and narratives of global discourses.

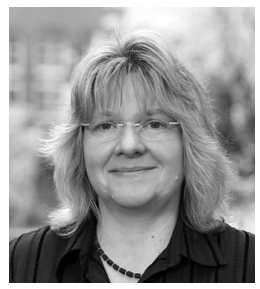

Cornelia Ulbert is the Executive Director of the Institute for Development and Peace (INEF) at the University of Duisburg-Essen. A Political Scientist specializing in International Relations, she researches global/transnational governance and international cooperation, with a particular focus on the role of international organizations, civil society and private actors in global health and international labor standards. 